\title{
Evolution of TCP Phase During Long Term Thermal Exposure in Several Re-Containing Single Crystal Superalloys
}

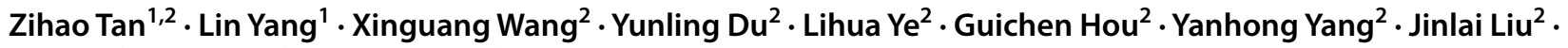 \\ Jide $\mathrm{Liu}^{2} \cdot$ Jinguo $\mathrm{Li}^{2} \cdot \mathrm{Yizhou} \mathrm{Zhou}^{2} \cdot \mathrm{Xiaofeng} \mathrm{Sun}^{2}$
}

Received: 23 July 2019 / Revised: 11 October 2019 / Published online: 17 December 2019

(C) The Chinese Society for Metals (CSM) and Springer-Verlag GmbH Germany, part of Springer Nature 2019

\begin{abstract}
The application and component designs of single crystal superalloys are restricted by the precipitation of topologically closed packed (TCP) phases, which can deteriorate the microstructural stability of the alloys severely. Limited researches concerning the type and morphology evolution of TCP phases under elevated temperature conditions have been reported previously. In the present work, three Re-containing single crystal alloys were designed to investigate TCP phase evolution via long term isothermal exposure tests at $1120^{\circ} \mathrm{C}$ while the effects of Re on the microstructural characteristic and elements segregation were also clarified. The results showed that the addition of Re increased the instability of the alloys and the volume fraction of the TCP phases exceeded $5 \mathrm{vol} \%$ when the Re content reached $3 \mathrm{wt} \%$. The increasing Re content had also raised the precipitation temperature of TCP phases but it did not change the type of them after long term aging; all the TCP particles were identified as $\mu$ phase in this study. Moreover, the elements segregation became considerably serious as Re addition increased constantly, which brought about various morphologies of the $\mu$ phase in the experimental alloys. In particular, the rod-like and needle-like $\mu$ phases demonstrated the typical orientation within $\gamma$ matrix while the blocky $\mu$ phase was dispersedly distributed in the space. No specific orientation relationship could be observed in the $\mu$ phase when the addition of Re exceeded certain threshold value.
\end{abstract}

Keywords Single crystal superalloys $\cdot$ Topologically closed packed (TCP) phase $\cdot$ Re $\cdot$ Elements segregation $\cdot$ Morphology

\section{Introduction}

Nickel-based single crystal superalloys are excellent structural materials which have been extensively applied to modern aero-engines, especially high-pressure turbine blades, since they can maintain remarkable creep and oxidation resistance at elevated temperatures [1-5]. With the

Available online at http://link.springer.com/journal/40195.

Lin Yang

yanglin318@126.com

$\triangle$ Xinguang Wang

xgwang11b@imr.ac.cn

1 School of Materials Science and Engineering, Shenyang University of Technology, 111 Shenliao Road, Shenyang 110870, China

2 Superalloys Division, Institute of Metal Research, Chinese Academy of Sciences, 72 Wenhua Road, Shenyang 110016, China continuous increase in turbine inlet temperatures, the service temperatures of single crystal superalloys are facing significant challenges. In recent years, many refractory elements including $\mathrm{Re}, \mathrm{W}$ and Mo have been added to enhance the solution strengthening effects, thus improving the service temperature of alloys [6-9]. Nevertheless, topologically closed packed (TCP) phases, such as $\sigma, \mu, P$ and $R$ phases have become common during service at high temperatures for the excessive addition of refractory elements $[10,11]$. In general, the harmful effects of TCP phases in single crystal superalloys can be summarized as the following: (a) depleting the solution strengthening elements in $\gamma$ matrix; (b) deteriorating the microstructural stability between $\gamma$ and $\gamma^{\prime}$ phases; (c) inducing creep porosities under elevated temperature conditions; (d) bringing about crack initiating and propagation in their vicinity $[9,12-14]$. Therefore, the effects of refractory elements on the formation and evolution of TCP phases must be clarified to optimize the composition designs of single crystal alloys. 
Huo et al. found that both the $\sigma$ phase and the $P$ phase were enriched in $\mathrm{Re}, \mathrm{W}, \mathrm{Cr}$ and Mo; however, the $\sigma$ phase consisted of more $\mathrm{Re}$ and $\mathrm{Cr}$ while the $P$ phase was composed of more Mo element [15]. They also pointed out the $\mu$ phase was enriched in Mo and they would transform into $R$ phase which contained more $\mathrm{Cr}$ at elevated temperatures [16]. However, in the work of Cheng et al., all the TCP phases after thermal exposure at $1100-1150{ }^{\circ} \mathrm{C}$ were identified as $\mu$ phase with more Re and $\mathrm{W}$ contents [17]. In the study of Tan et al. about Ru-containing single crystal superalloys, the TCP phases were also deduced as $\mu$ phase after long term aging at $1100{ }^{\circ} \mathrm{C}$ [18]. To conclude, the effects of refractory elements on the type of TCP phases in single crystal superalloys after thermal exposure at elevated temperature are still in controversy. Moreover, the morphology of TCP phase is also of great significance to the mechanical properties in single crystal alloys. Tian et al. proposed that the strip-like $\mu$ phase would bring about more stress concentration and the reduction in creep life compared to blocky $\mu$ phase [19].

Compared to other refractory elements, Re has attracted more attention for the disputable effects in single crystal superalloys, and the previous researches have been mainly focused on its promotion to TCP phases and deterioration to microstructural stability [20, 21]. However, few literature has reported the effects of Re on the evolution of TCP phase during long term thermal exposure, especially under elevated temperature conditions. In the present study, several single crystal superalloys with different Re additions were designed to investigate the role Re had played in the evolution of TCP phase during long term aging. The type and morphology of TCP phases were identified while the segregation behaviors of Re and other refractory elements were also measured.

\section{Experimental}

In the present work, three experimental superalloys are named by Alloy $1 \mathrm{Re}, 2 \mathrm{Re}$ and $3 \mathrm{Re}$ and the chemical compositions of them are listed in Table 1 . The tested alloys have similar composition except for different Re additions. The single crystal rods were directionally solidified along
[001] orientation, and the withdrawal rate was maintained at $6 \mathrm{~mm} / \mathrm{min}$.

Both differential scanning calorimeter (DSC) and metallurgical analysis methods were used to determine the solution temperatures of the experimental alloys. Considering the similar incipient melting temperatures, the same heat treatment regimes were carried out on each alloy as follows:

$$
\begin{aligned}
& 1300^{\circ} \mathrm{C} \times 1 \mathrm{~h}+1305^{\circ} \mathrm{C} \times 3 \mathrm{~h}+1315^{\circ} \mathrm{C} \times 4 \mathrm{~h}, \\
& \text { air cooling }(\mathrm{AC}) \rightarrow 1080{ }^{\circ} \mathrm{C} \times 6 \mathrm{~h}, \\
& \mathrm{AC} \rightarrow 870{ }^{\circ} \mathrm{C} \times 24 \mathrm{~h}, \quad \text { AC. }
\end{aligned}
$$

After standard heat treatments, specimens of the experimental alloys were cut into 6-8 $\mathrm{mm}$ for long term thermal exposure at $1120{ }^{\circ} \mathrm{C}$ to investigate the microstructural stability and the evolution of TCP phases. The microstructure after exposure for 100, 200, 500 and $1000 \mathrm{~h}$ was examined by optical microscopy (OM) and Inspect F50 scanning electron microscopy (SEM), and the metallographic specimens were polished and etched with $4 \mathrm{~g} \mathrm{CuSO}_{4}+10 \mathrm{ml} \mathrm{HCl}+20 \mathrm{ml}$ $\mathrm{H}_{2} \mathrm{O}$. The selected area diffraction patterns (SADP) of TCP phases were obtained by JEM 2100 transmission electron microscopy (TEM) equipped with an EDS system to identify the transformation of the TCP phases. Specimens for TEM observation were cut normal to the [001] orientation and mechanically grinded to approximately $40 \mu \mathrm{m}$. These foils were then electrochemically thinned using a twin jet polisher in a solution of $10 \%$ perchloric and $90 \%$ ethanol at $-20{ }^{\circ} \mathrm{C}$.

Furthermore, an electron probe microanalyzer (EPMA 1600 , Shimadzu) was used to elucidate the elements segregation behavior. In view of the fine microstructure after standard heat treatments, a special coarsening heat treatment was carried out; hence, the chemical compositions of the $\gamma^{\prime}$ phase and $\gamma$ matrix could be detected accurately.

\section{Results}

\subsection{Initial Microstructure}

Figure 1a displays the as-cast structure normal to [001] orientation in the experimental alloys. It was seen that the dendritic cores and interdendritic regions were well distributed
Table 1 Chemical composition of the three experimental single crystal superalloys (wt \%)

\begin{tabular}{llllllll}
\hline Alloy & $\mathrm{Al}$ & $\mathrm{Co}$ & $\mathrm{Cr}$ & $\mathrm{Ti}$ & $\mathrm{W}+\mathrm{Mo}+\mathrm{Ta}$ & $\mathrm{Re}$ & $\mathrm{Ni}$ \\
\hline $1 \operatorname{Re}$ & 5.42 & 7.99 & 7.96 & 0.71 & 16.04 & 1.02 & $\mathrm{Bal}$ \\
$2 \operatorname{Re}$ & 5.43 & 8.01 & 7.95 & 0.71 & 16.05 & 2.03 & $\mathrm{Bal}$ \\
$3 \operatorname{Re}$ & 5.41 & 8.00 & 7.95 & 0.70 & 16.01 & 3.01 & $\mathrm{Bal}$ \\
\hline
\end{tabular}



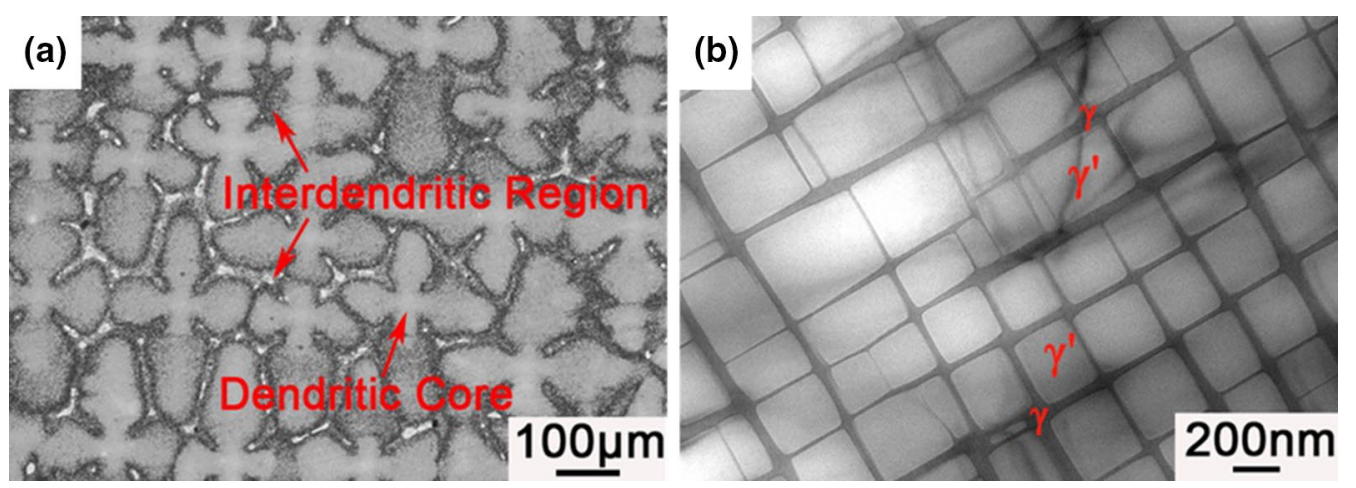

Fig. 1 Morphologies of the experimental alloys: a as-cast structure, $\mathbf{b}$ heat-treated structure

and the micro-segregation was distinct. The heat-treated microstructures of the tested alloys with different Re additions are shown in Fig. 1b. The $\gamma^{\prime}$ phase with perfect cubic shape was found embedded in the $\gamma$ matrix uniformly in the three alloys. The volume fractions of the cubic $\gamma^{\prime}$ phase were measured to be approximately $60-65 \mathrm{vol} \%$ while the average $\gamma^{\prime}$ size was among $0.29-0.32 \mu \mathrm{m}$.

\subsection{Microstructure After Long Term Thermal Exposure}

Figure 2 illustrates the microstructure evolution of Alloy 1 Re during long term aging at $1120^{\circ} \mathrm{C}$. After $100 \mathrm{~h}$, the rafted $\gamma^{\prime}$ phase was clear in both dendritic and interdendritic regions while few TCP phase was found. The TCP phase began to precipitate when the aging time came to
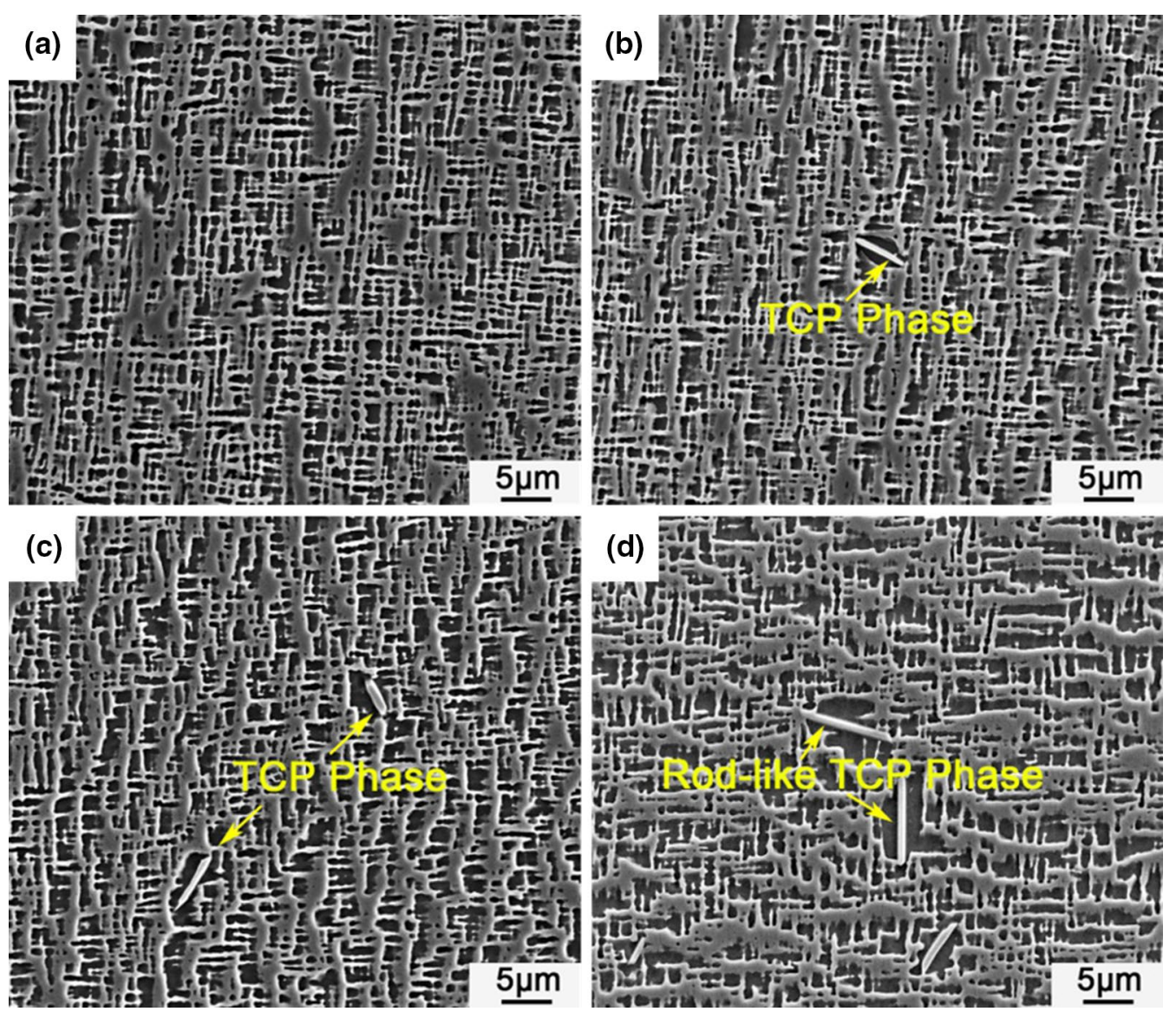

Fig. 2 SEM images of Alloy 1 Re after long term aging at $1120^{\circ} \mathrm{C}$ with different time: a $100 \mathrm{~h}, \mathbf{b} 200 \mathrm{~h}, \mathbf{c} 500 \mathrm{~h}, \mathbf{d ~} 1000 \mathrm{~h}$ 
$200 \mathrm{~h}$ and their growth was relatively moderate with time extending. During 500-1000 h, no significant changes were observed except for slight increase in the length and amount of TCP phases which dominantly presented rodlike morphology, as shown in Fig. 2c, d. Therefore, it can be inferred that Alloy 1Re exhibits perfect microstructural stability.

The microstructural stability of Alloy 2Re was relatively worse compared to Alloy 1Re, as shown in Fig. 3. Both rafted structures and the TCP phase were observed after aging for $100 \mathrm{~h}$ and the initial rod-like TCP phase gradually transformed into needle-like morphology from 200 to $500 \mathrm{~h}$. As aging time prolonged to $1000 \mathrm{~h}$, TCP phases with long needle shape could be clearly seen to cut through the $\gamma^{\prime}$ lamellar and $\gamma$ matrix, which was similar to the observation of DD6 single crystal alloys after $1100{ }^{\circ} \mathrm{C}$ aging [22]. Besides, the needle-like TCP phase precipitated in a specific orientation, i.e., at the angle of $45^{\circ}$ along the $\gamma^{\prime}$ rafting direction, as shown in Fig. 3d. Note that further nucleation of the TCP phase could hardly be found after $200 \mathrm{~h}$ regardless of the rapid growth rate, which manifested that the nucleation process had been restrained at the early stage of aging.
Alloy 3Re demonstrated the worst microstructural stability among the experimental alloys under elevated temperature condition, as shown in Fig. 4. Several fine TCP phases presented just after $100 \mathrm{~h}$ of thermal exposure and the kinetics of the TCP phase nucleation were considerably accelerated compared to previous two alloys. From $200 \mathrm{~h}$ to $500 \mathrm{~h}$, large quantities of the blocky TCP phases were diffusely distributed in dendritic areas; however, no obvious variation was found in the size of the precipitates with the extension of time. After $1000 \mathrm{~h}$, the typical rafted structures vanished and the fine blocky TCP phase had occupied the dendritic regions which deteriorated the microstructural stability of the alloy entirely.

Table 2 lists the volume fractions of the TCP phases in the three single crystal alloys during long term aging. It is evident that the increase of Re contributes to the precipitation of detrimental phases while the volume fraction of the TCP phase in Alloy 3Re has exceeded 5 vol\% after $1000 \mathrm{~h}$ isothermal exposure, which indicates that the alloy has lost its microstructural stability to considerable extent. Furthermore, the morphologies of the TCP phases transformed from short rod-like to long needle-like morphology and then blocky shape with increasing Re addition. Based on above
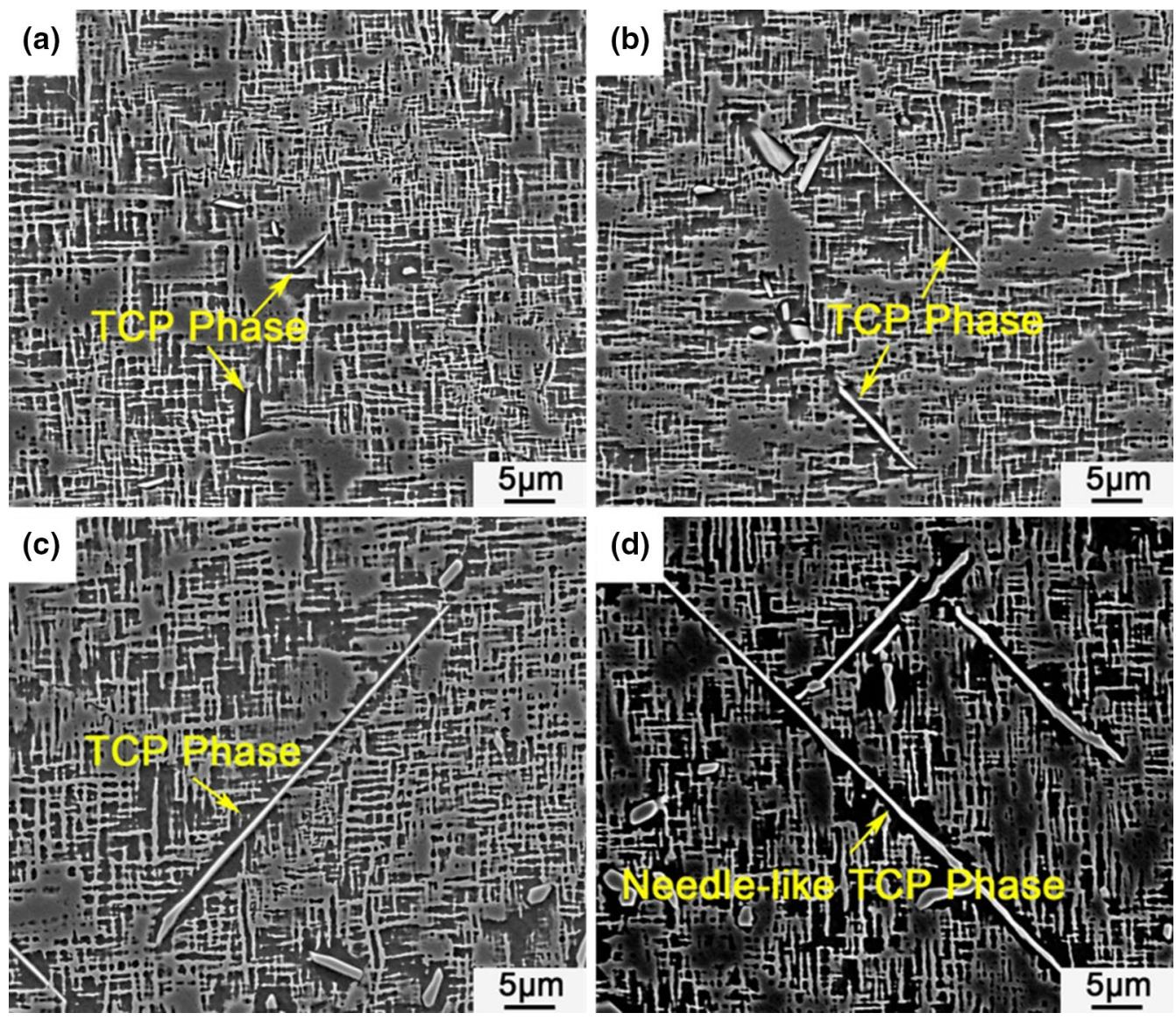

Fig. 3 SEM images of Alloy 2 Re after long term aging at $1120^{\circ} \mathrm{C}$ with different time: a $100 \mathrm{~h}, \mathbf{b} 200 \mathrm{~h}, \mathbf{c} 500 \mathrm{~h}, \mathbf{d} 1000 \mathrm{~h}$ 

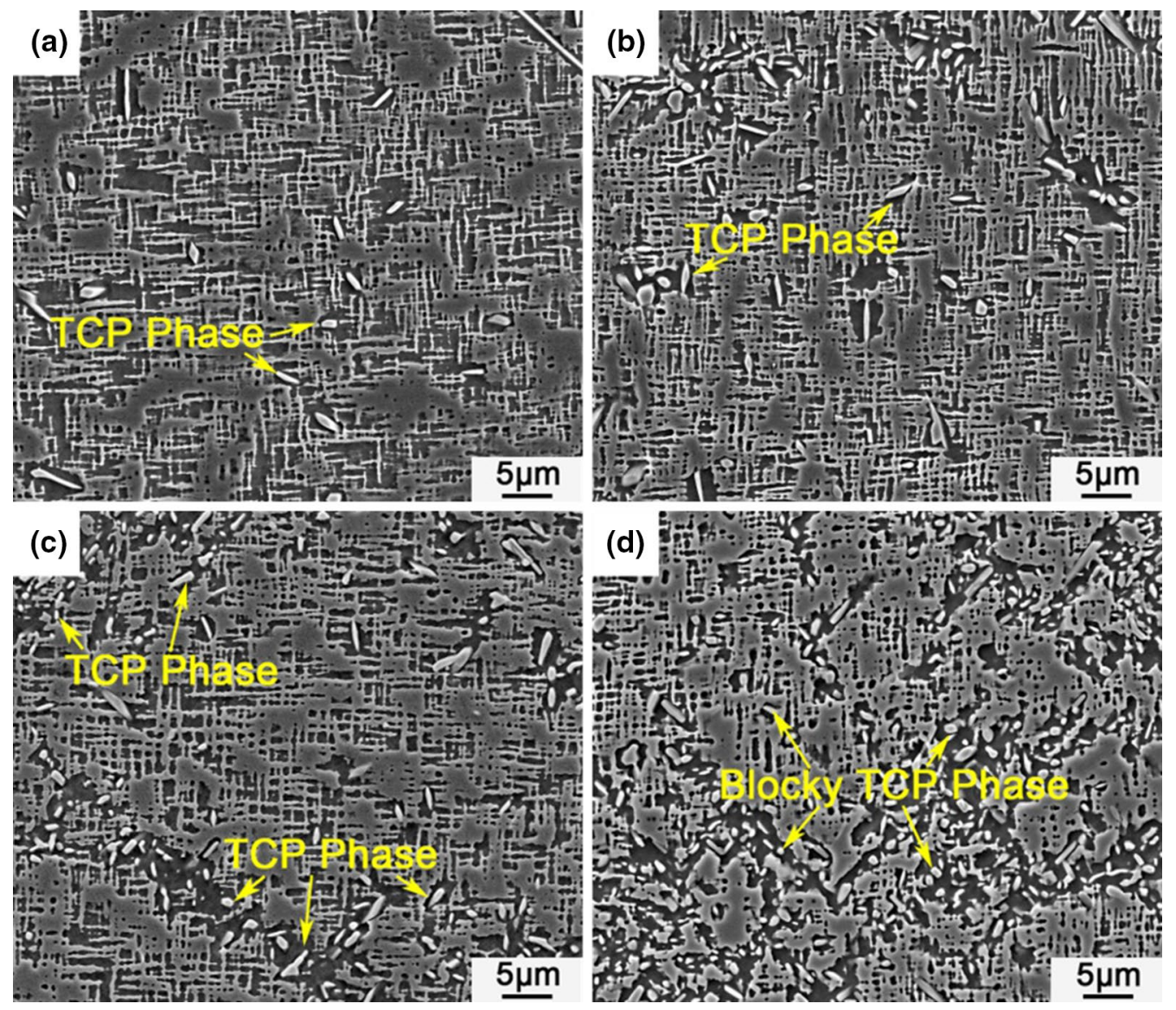

Fig. 4 SEM images of Alloy 3Re after long term aging at $1120^{\circ} \mathrm{C}$ with different time: a $100 \mathrm{~h}, \mathbf{b} 200 \mathrm{~h}, \mathbf{c} 500 \mathrm{~h}, \mathbf{d} 1000 \mathrm{~h}$

Table 2 Volume fraction of the $\mu$ phase in three experimental single crystal superalloys

\begin{tabular}{llll}
\hline Alloy & $1 \mathrm{Re}$ & $2 \mathrm{Re}$ & $3 \operatorname{Re}$ \\
\hline $100 \mathrm{~h}($ vol\%) & $<0.01$ & $0.28 \pm 0.09$ & $0.92 \pm 0.31$ \\
$200 \mathrm{~h}($ vol\%) & $0.11 \pm 0.04$ & $0.92 \pm 0.28$ & $2.80 \pm 1.10$ \\
$500 \mathrm{~h}($ vol\%) & $0.29 \pm 0.11$ & $1.54 \pm 0.43$ & $3.30 \pm 1.23$ \\
$1000 \mathrm{~h}(\operatorname{vol} \%)$ & $0.69 \pm 0.25$ & $3.57 \pm 1.19$ & $5.77 \pm 2.03$ \\
\hline
\end{tabular}

observations, it can be deduced that the minor adjustment of Re addition has brought about significant influence on the precipitation behavior of the TCP phase and corresponding microstructural stability. Further discussion is required to explain effects of Re on the morphological evolution of the TCP phase.

\subsection{Identification of the TCP Phase}

Figure 5 shows bright TEM images and the corresponding selected area diffraction patterns of the typical TCP particles after $1000 \mathrm{~h}$ aging in the experimental alloys with different Re additions. As mentioned above, the TCP phases in Alloy
$1 \mathrm{Re}, 2 \mathrm{Re}$ and $3 \mathrm{Re}$ demonstrated rod-like, needle-like and blocky-like morphology, respectively; however, these TCP particles were all characterized to be $\mu$ phase by selected area diffraction analysis. Therefore, it is rational to conclude that the increasing addition of Re can exert influence on the TCP morphology but it has not changed the type of the precipitations. It is noteworthy that some parallel lamellar structures were observed inside the $\mu$ phase and they could be regarded as planar defects like the stacking faults, which is in concordance with the previous reports [23, 24]. Moreover, the TCP particles were found mainly surrounded by the rafted $\gamma^{\prime}$ phase in consideration of the excessive consumption of refractory elements like $\mathrm{Re}, \mathrm{W}$ and $\mathrm{Cr}$ in $\gamma$ matrix, as shown in Fig. 5.

\subsection{Chemical Composition of the $\mu$ Phase}

The primary chemical compositions of the $\mu$ phase in the alloys with different Re additions containing after $1000 \mathrm{~h}$ long term exposure were obtained by TEM-EDS, as listed in Table 3. The $\mu$ phases in the three alloys were all enriched in $\mathrm{Cr}$, Co, Mo and Re, additionally, they contained especially high concentration of $\mathrm{W}$ which manifested that $\mathrm{W}$ was the 

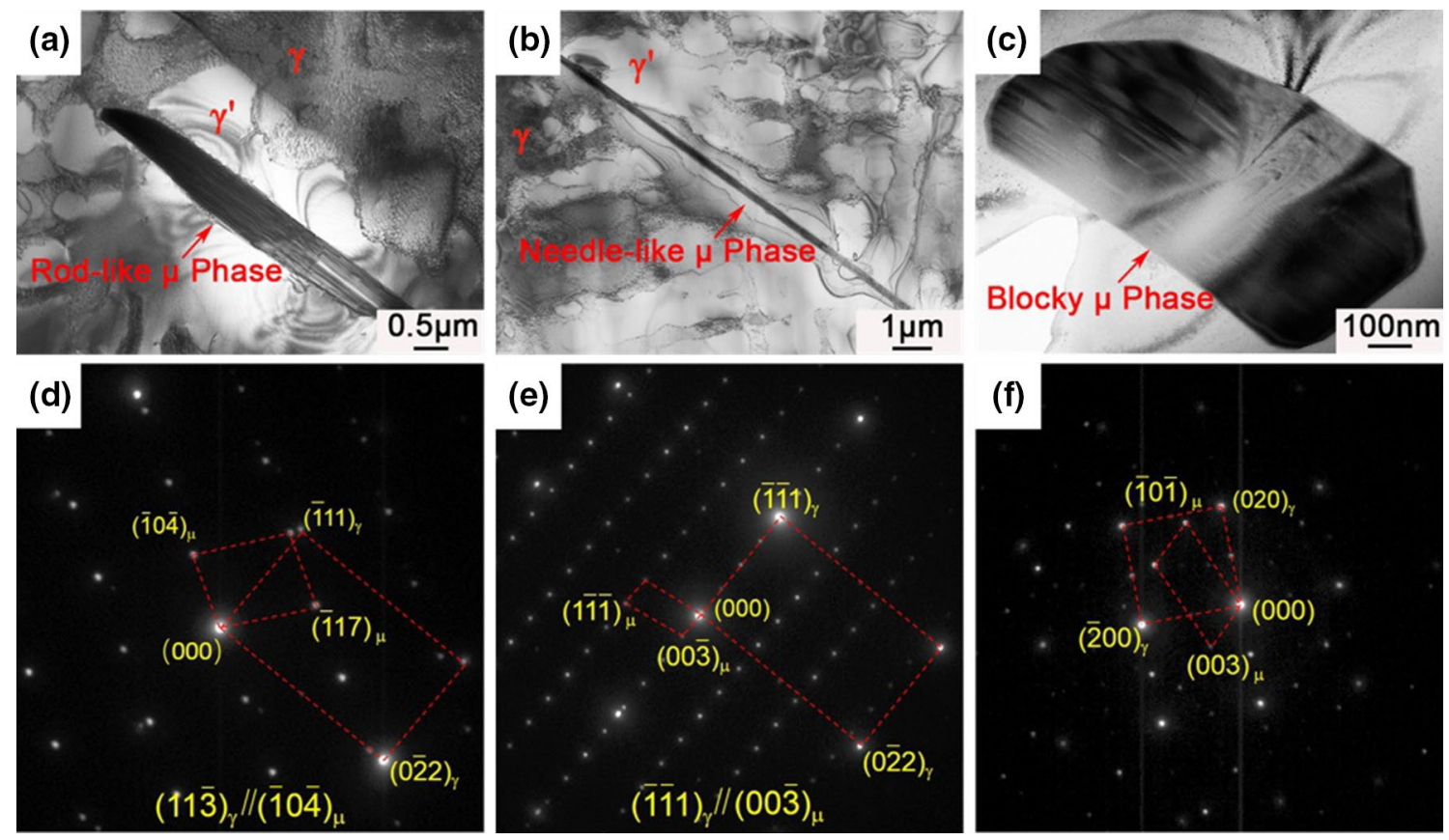

Fig. 5 Bright TEM images and SADP of the $\mu$ phase in three experimental alloys after $1000 \mathrm{~h}$ aging at $1120^{\circ} \mathrm{C}$ : a, d Alloy 1 Re, b, e Alloy 2 Re, c, f Alloy $3 R e$

Table 3 Primary composition of the $\mu$ phase in the three single crystal superalloys after $1000 \mathrm{~h}$ aging at $1120^{\circ} \mathrm{C}($ at $\%)$

\begin{tabular}{lllllll}
\hline Alloy & Cr & Co & W & Mo & Re & Ni \\
\hline $1 \operatorname{Re}$ & 15.2 & 12.3 & 32.0 & 8.3 & 10.6 & 21.6 \\
$2 \operatorname{Re}$ & 14.5 & 11.8 & 26.8 & 7.1 & 13.8 & 26.0 \\
$3 \operatorname{Re}$ & 16.0 & 12.0 & 25.7 & 7.0 & 17.4 & 22.0 \\
\hline
\end{tabular}

pivotal forming element in the $\mu$ phase. The concentration of $\operatorname{Re}$ in the $\mu$ phase was correspondingly promoted with the increase in its addition in the alloys, i.e., the blocky $\mu$ phase in Alloy $3 \mathrm{Re}$ contained the most Re elements. What was interesting was that the total contents of $(\mathrm{Cr}+\mathrm{Co}+\mathrm{Mo})$ were generally kept unchanged in spite of the morphology evolution in the $\mu$ phase. Furthermore, considering the severe depletion of $\mathrm{Al}, \mathrm{Ta}$ and $\mathrm{Ti}$ in the $\mu$ phase, they were basically negligible and not listed.

\section{Discussion}

\subsection{Thermodynamic Calculation}

The equilibrium phase diagrams of the three single crystal alloys were calculated via Thermal-Calc software (date base: TTNi7, Institute of Metal Research, Chinese Academy of Sciences) to further verify the precipitate behavior of the TCP phase. The temperature for calculation was chosen ranging from 600 to $1400{ }^{\circ} \mathrm{C}$, as shown in Fig. 6. It was apparent that $2 \mathrm{wt} \%$ and $3 \mathrm{wt} \% \mathrm{Re}$ addition increased the precipitation temperature of the $\sigma$ phase and $\mu$ phase compared to Alloy $1 \mathrm{Re}$. No evident changes were observed concerning the precipitation temperature of the $\mu$ phase between Alloy $2 \mathrm{Re}$ and $3 \mathrm{Re}$, but the $P$ phase would begin to appear at about $1150{ }^{\circ} \mathrm{C}$ in the Alloy $3 \mathrm{Re}$. Nevertheless, in the work of Zhou et al. about DD6 single crystal superalloy, the $P$ phase would precipitate after annealing at $1100{ }^{\circ} \mathrm{C}$ [25]. The precipitation behavior of $P$ phase has the necessity to be figured out in the future works. In the present work, the exposure temperature was kept at $1120^{\circ} \mathrm{C}$; hence, the vast majority of TCP phases in the three alloys were inferred to be $\mu$ phase, which conformed to the TEM identification.

In addition, the variation of $\mu$ phase amount in the three experimental alloys calculated by Thermal-Calc was also consistent with the above experimental results, i.e., the volume fraction of the $\mu$ phase increased with the increase of Re content in the alloys. In summary, the addition of Re could accelerate the precipitation of the $\mu$ phase and contribute to the formation of other TCP phases under elevated temperature conditions, thus promoting the instability of the microstructure in the experimental alloys. 

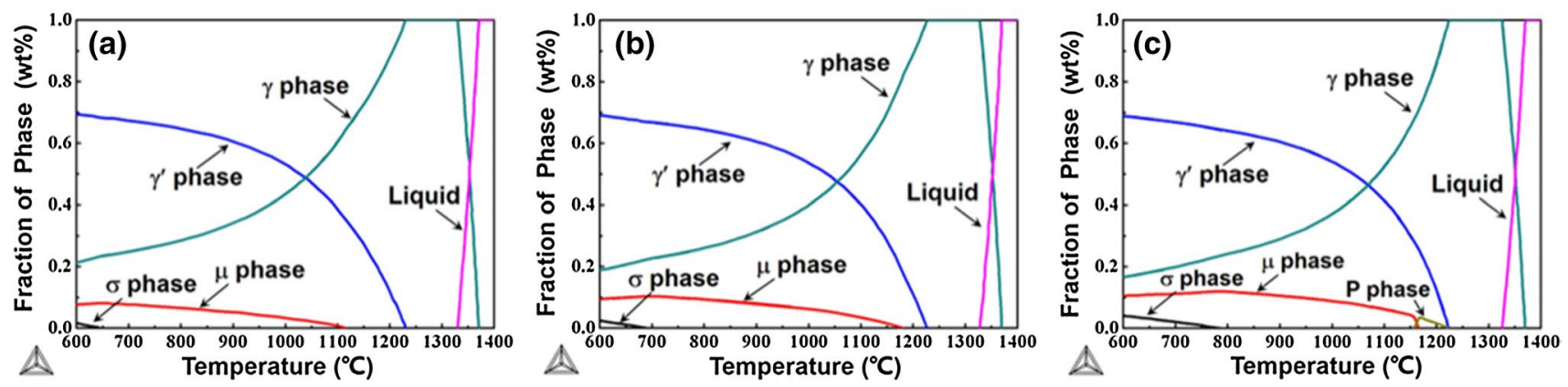

Fig. 6 Equilibrium phase diagrams of the experimental alloys by thermal-calc software: a Alloy 1 Re, b Alloy $2 \operatorname{Re}, \mathbf{c}$ Alloy $3 R e$

\subsection{Effect of Re on Elements Segregation}

The element segregations between the dendritic cores and interdendritic areas, the $\gamma^{\prime}$ phase and $\gamma$ matrix are of great significance to the precipitation of $\mu$ phase $[17,21,26]$. The different Re additions led to distinct elements segregation behaviors which thereby causing variations in the amount and morphology of the $\mu$ phase.

The segregation ratio between the dendritic cores and interdendritic areas was defined by Eq. (1) as follows:

$K=C_{d} / C_{i}$,

where $C_{d}$ and $C_{i}$ were the average chemical compositions of elements in the dendritic cores and interdendritic regions, respectively. The as-cast specimens were analyzed by EPMA to obtain the chemical compositions of the dendritic structures, and the calculated segregation ratios in the three tested alloys are shown in Fig. 7a. On the one hand, considering the high melting points of element $\mathrm{W}$ and $\mathrm{Re}$, they would firstly segregate to the dendrite arms and then interdendritic areas; therefore, they were identified as strong negative segregation elements $(K<1)$. On the contrary, elements $\mathrm{Al}, \mathrm{Ti}$, Ta and Mo were characterized to be positive segregation elements which chiefly segregated to interdendritic regions. On the other hand, the addition of Re facilitated the segregation of $\mathrm{Al}, \mathrm{Ti}$ and $\mathrm{Ta}$ to interdendritic regions and the distribution of $\mathrm{W}$ to dendritic cores. Note that the dendritic segregation of Re became rather serious with increasing Re content in the alloys. Hence, it can be inferred that the dendrite arms of Alloy 3Re have accommodated considerable refractory elements compared to other two alloys.

Moreover, it is known that the TCP phases are precipitated from the supersaturated $\gamma$ matrix under elevated temperature conditions; thus, the influence of $\mathrm{Re}$ on the elements partitioning between the $\gamma^{\prime}$ phase and $\gamma$ matrix has the necessity to be clarified. The partition ratio $(R)$ of each alloying element was calculated through Eq. (2) as follows:

$R=C_{i g} / C_{i g^{\prime}}$.

There is no doubt that $R$ is used to characterize the preferential partition to the $\gamma$ matrix and $\gamma^{\prime}$ phase of the alloying elements, respectively. Hence, it can be inferred that $R>1$ manifests the preferential distribution to $\gamma$ matrix while $R<1$ indicates the constituent element of $\gamma^{\prime}$ phase. Figure $7 \mathrm{~b}$ illustrates the calculated partition coefficient of each alloying element, it is obvious that the partition coefficient of Re has (a)

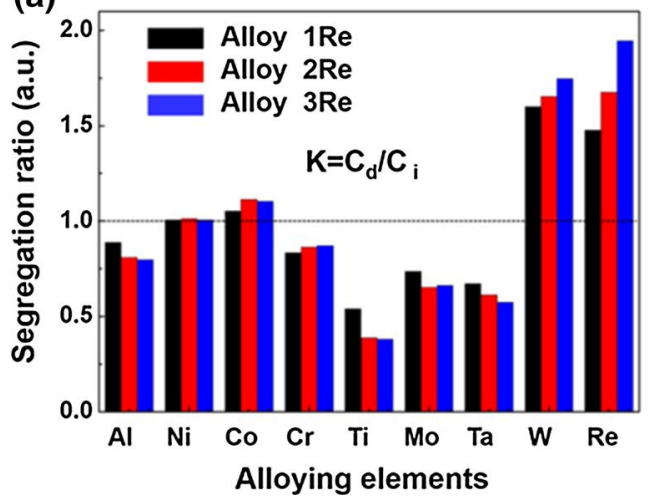

(b)

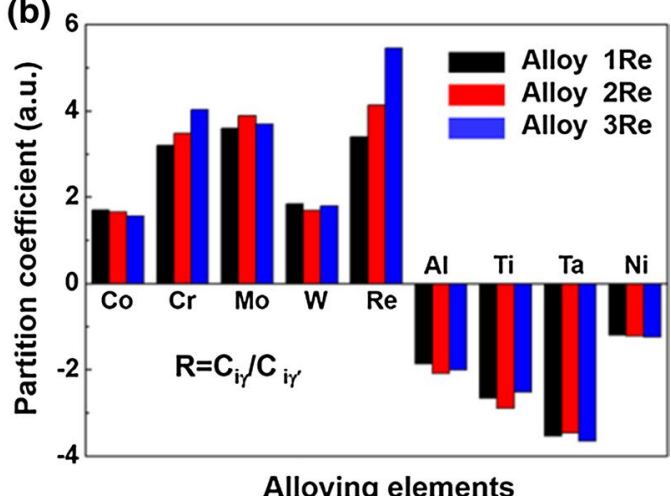

Alloying elements

Fig. 7 Effects of Re on the elements distribution in the three experimental alloys: a segregation ratio, b partition coefficient 
increased dramatically while some improvements are also found in the coefficient of $\mathrm{Cr}$, with increasing $\mathrm{Re}$ addition in the alloys. No significant changes were observed in the partition coefficients of other elements. As reported in the previous studies [27-30], the concentration of $\mathrm{Re}, \mathrm{W}, \mathrm{Cr}$ and Mo in $\gamma$ matrix was harmful to the microstructural stability for the promotion of TCP precipitates. Therefore, the distribution behaviors of Re and Cr, especially the strong segregation of $\mathrm{Re}$, are believed to be the primary reason which may rationalize the various morphologies of the TCP phases in the experimental alloys.

\subsection{Effect of Re on the Precipitation of $\mu$ Phase}

According to the theory of solids transformation [31], the critical nucleus radius $r^{*}$ and nucleation energy $\Delta G^{*}$ are determined by the extent of supersaturation in $\gamma$ matrix. Based on the partition coefficients in the three alloys, the addition of Re has promoted the level of $\gamma$ supersaturation evidently. Therefore, both $r^{*}$ and $\Delta G^{*}$ would be decreased with increasing Re content, i.e., the nucleation behavior of the $\mu$ phase was promoted when the addition of Re was increased, which was consistent with the experimental results as well as previous research [17].

Moreover, typical orientations of the majority particles, viz. approximately $45^{\circ}$ along the rafted $\gamma^{\prime}$ phase, could be observed in Alloy $1 \mathrm{Re}$ and $2 \mathrm{Re}$ at the early stage of long term aging. In Alloy $3 \mathrm{Re}$, however, numerous blocky-like $\mu$ phases precipitated at $100-200 \mathrm{~h}$ aging and no specific orientations could be found. From the aspect of nucleation energy, the $\mu$ phase was believed to precipitate at the typical coherent interface to minimize the energy consumption, when the $\gamma$ supersaturation was relatively low during thermal exposure [32, 33]. For Alloy $3 \mathrm{Re}$, however, in view of the high supersaturation of $\operatorname{Re}$ and $\mathrm{Cr}$ in $\gamma$ matrix, interactions between these solution elements may occur, which give rise to the further element segregations. The element segregations as well as lattice imperfections help accelerate the atomic diffusion rate and lower the nucleation barrier of the TCP phase [34]. Hence, the blocky-like $\mu$ phase can precipitate from the $\gamma$ matrix straightly and become less dependent on the low-index crystal planes to nucleate, i.e., no distinct coherent relationship can be observed between the particles and matrix.

Based on the above analysis, schematic illustration of the possible precipitate behavior of the $\mu$ phase at the early stage of aging is drawn in Fig. 8. It was overt that the initial $\mu$ phase exhibited short rod-like morphology in Alloy $1 \mathrm{Re}$ and $2 \mathrm{Re}$, in addition, plenty of tiny blocky-like $\mu$ phases were dispersedly distributed in the space, as a consequence of severe elements segregation caused by the higher content of Re in Alloy 3Re.

Further growth behavior of the TCP particles, especially the growth dynamics and morphology evolution, can be determined by multiple factors. Actually, different interface coherence between the precipitations and matrix plays a crucial role in the growth process, which can even exert influence on the mechanical properties of the alloys [35-38]. According to last section, the $\mu$ phase exhibited short rod-like shape after nucleation in Alloy $1 \mathrm{Re}$ and $2 \mathrm{Re}$; therefore, the semicoherent side and incoherent edge of the $\mu$ phase were believed to have different migration rates [39]. The smoothly curved incoherent facets tend to be the dominant growing orientation while the migration behavior of semicoherent interface may be impeded. Expressly, the lengthening rate of rod-like or needle-like $\mu$ phase can be considerably influenced by the element supersaturation in $\gamma$ matrix [39]. In this work, the supersaturation of the

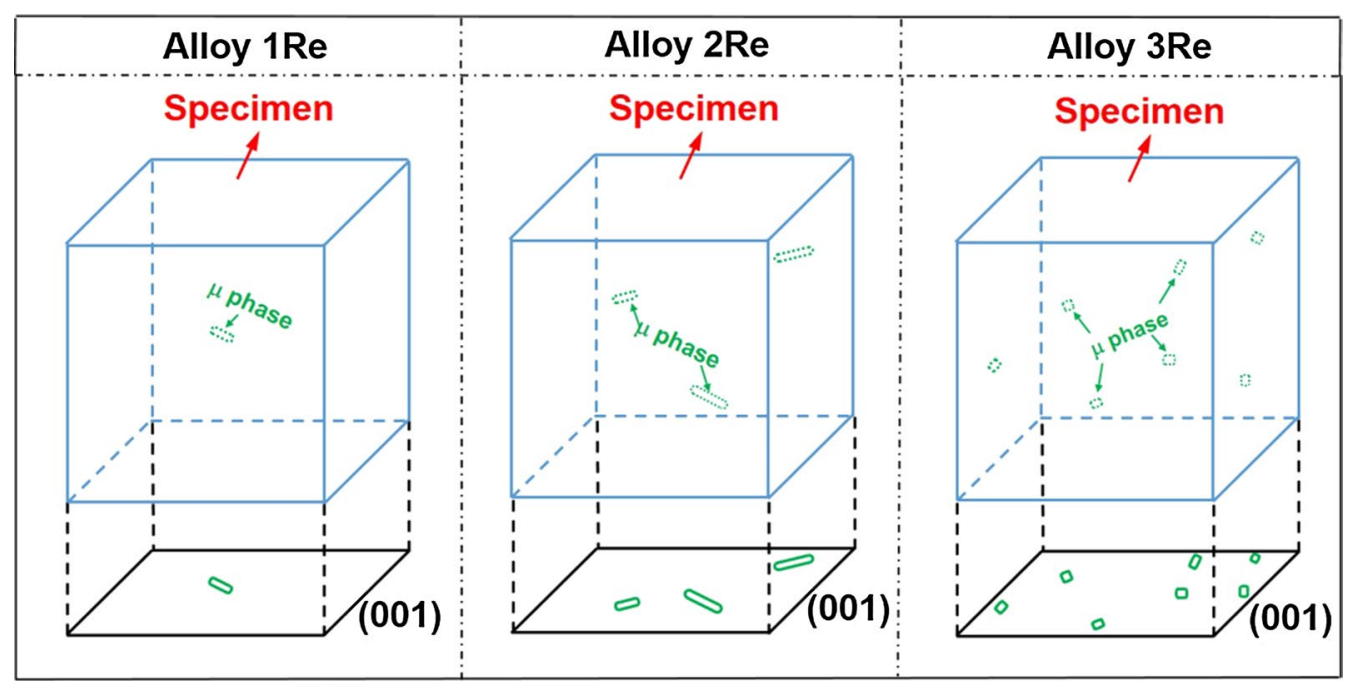

Fig. 8 Schematic illustration of possible precipitate behavior of the $\mu$ phase at early stage in the three experimental single crystal alloys 


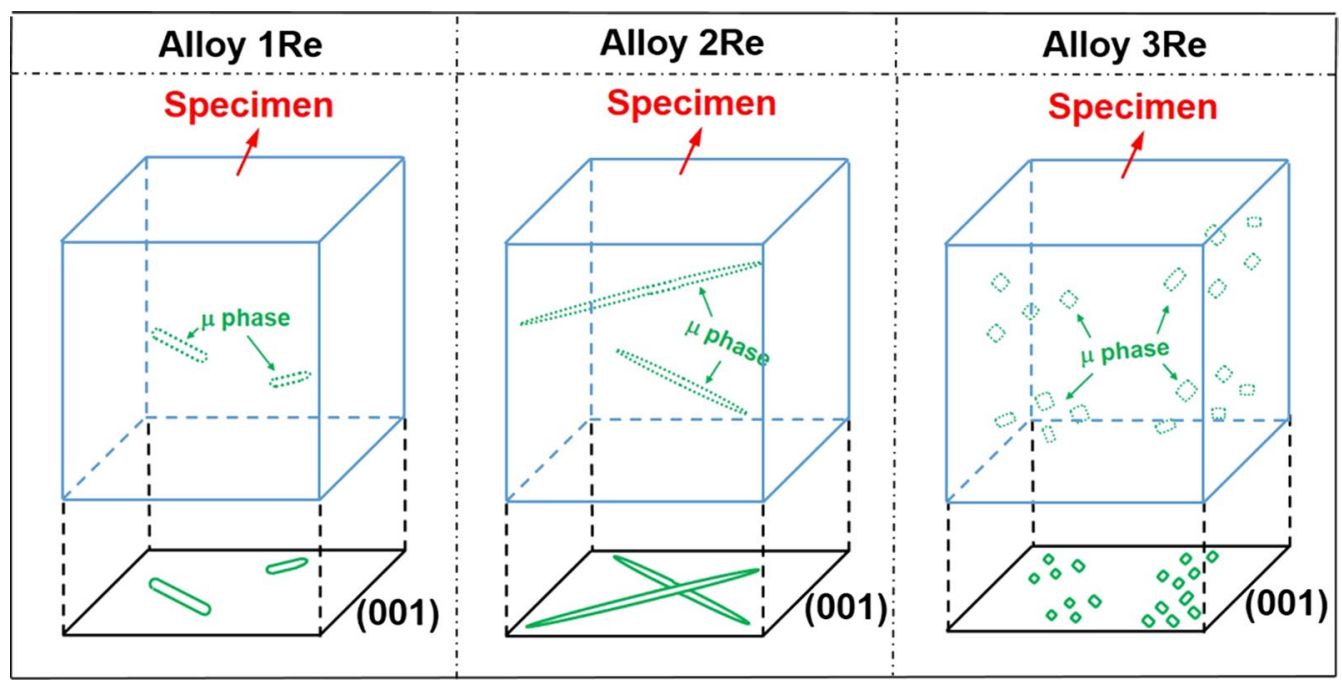

Fig. 9 Schematic illustration of possible final morphologies of the $\mu$ phase in the three experimental single crystal alloys

refractory elements was promoted as the addition of Re increased; therefore, it could be inferred that Re addition contributed to the growth process of the $\mu$ phase while the lengthening rate had been promoted in Alloy 2Re. Consequently, the morphology of the $\mu$ phase in Alloy 1Re and 2Re exhibited rod-like and long needle-like, respectively, after $500-1000 \mathrm{~h}$ isothermal exposure at $1120{ }^{\circ} \mathrm{C}$.

According to TEM observation, it was obvious that the rod-like and needle-like $\mu$ phases exhibited good relationships with $\gamma$ matrix and the low-index crystal planes were used to obtain selected area diffraction patterns. Nevertheless, it was hard to acquire the crystallographic orientations between the blocky $\mu$ phase and matrix, which conformed to the inference in the previous section. For Alloy 3Re, a relatively fast atomic absorption existed in the blocky $\mu$ phase on account of the high concentration of refractory elements during long term aging [36], thus generating considerable lattice strain energy between the precipitation and matrix. The $\mu$ phase particles have the necessity to tilt the growth direction constantly to match this energy. Controlled by multiple planes, no dominant orientation could be observed during the growing period of the blocky $\mu$ phase while the growth rate of these particles was thereby sluggish. Schematic illustrations of the final morphology of the $\mu$ phase in the three experimental alloys were drawn to illustrate the morphologies evolution caused by various addition of Re, as shown in Fig. 9. Affected by the comprehensive functions of Re addition, the TCP particles demonstrated distinct morphologies in the three experimental single crystal alloys after long term aging under elevated temperature ultimately.

\section{Conclusions}

Evolution characteristic of the TCP phase during long term thermal exposure and the effects of Re on the TCP type and morphology were systematically investigated in this work. The main conclusions could be drawn as follows:

(1) Addition of Re contributed to the precipitation of TCP phases, which rationalized the considerable decrease in microstructural stability under elevated temperature condition.

(2) All the TCP phases were characterized to be $\mu$ phase enriched in W, Cr and Re; however, the particles morphology transformed from rod-like to long needle-like and then blocky-like as the Re content increased in the alloys.

(3) Higher Re content aggravated the element segregations between the dendritic arms and interdendritic regions, the $\gamma^{\prime}$ phase and $\gamma$ matrix. Meanwhile, the precipitation temperature of the $\mu$ phase could be raised by the addition of Re.

Acknowledgements This work was financially supported by the State Key Lab of Advanced Metals and Materials Open Fund under Grant No. 2018-Z07, the National Science and Technology Major Project under Grant No. 2017-VI-0002-0072, the National Key R\&D Program of China under Grant No. 2017YFA0700704, the National Natural Science Foundation of China (NSFC) under Grant Nos. 51601192, 51671188 and the Youth Innovation Promotion Association, Chinese Academy of Sciences. The authors are grateful to K. Xu (Institute of Metal Research, Chinese Academy of Sciences) for the pivotal thermodynamic calculations. 


\section{References}

[1] T. Jin, Y.Z. Zhou, X.G. Wang, J.L. Liu, X.F. Sun, Z.Q. Hu, Acta Metall. Sin. 51, 1153 (2015). (in Chinese)

[2] L. Liu, J. Meng, J.L. Liu, H.F. Zhang, X.D. Sun, Y.Z. Zhou, Acta Metall. Sin. Engl. Lett. 32, 381 (2019)

[3] R.C. Reed, The Superalloys: Fundaments and Applications (Cambridge University Press, Cambridge, 2006)

[4] Y.B. Hu, T.S. Cao, C.Q. Cheng, L. Zhang, J. Zhao, Appl. Surf. Sci. 209, 484 (2019)

[5] X.G. Wang, J.L. Liu, T. Jin, X.F. Sun, Y.Z. Zhou, Z.Q. Hu, J.H. Do, B.G. Choi, I.S. Kim, C.Y. Jo, Mater. Sci. Eng., A 406, 626 (2015)

[6] J. Zhang, L.H. Lou, Acta Metall. Sin. 54, 1637 (2018). (in Chinese)

[7] S.G. Tian, Y. Su, B.J. Qian, X.F. Yu, A.A. Li, Mater. Des. 236, 37 (2012)

[8] Q.Q. Ding, S.Z. Li, L.Q. Chen, X.D. Han, Z. Zhang, Q. Yu, J.X. Li, Acta Mater. 154, 137 (2018)

[9] X.F. Sun, T. Jin, Y.Z. Zhou, Z.Q. Hu, Mater. China 31, 1 (2012)

[10] F. Sun, J.X. Zhang, P. Liu, Q. Feng, X.D. Han, S.C. Mao, J. Alloys Compd. 536, 80 (2012)

[11] B. Seiser, R. Drautz, D.G. Pettifor, Acta Mater. 59, 749 (2011)

[12] C.M.F. Rae, R.C. Reed, Acta Mater. 49, 4113 (2001)

[13] M.V. Acharya, G.E. Fuchs, Mater. Sci. Eng., A 381, 143 (2004)

[14] Z.K. Zhang, Z.F. Yue, J. Alloys Compd. 746, 84 (2018)

[15] J.J. Huo, Q.Y. Shi, Y.R. Zheng, Q. Feng, Mater. Charact. 124, 73 (2017)

[16] J.J. Huo, Q.Y. Shi, Y.R. Zheng, Q. Feng, J. Alloys Compd. 715, 460 (2017)

[17] K.Y. Cheng, C.Y. Jo, T. Jin, Z.Q. Hu, J. Alloys Compd. 536, 7 (2012)

[18] X.P. Tan, J.L. Liu, T. Jin, Z.Q. Hu, H.U. Hong, B.G. Choi, I.S. Kim, C.Y. Jo, Mater. Sci. Eng., A 528, 8381 (2011)

[19] S.G. Tian, J. Wu, D.L. Shu, Y. Su, H.C. Yu, B.J. Qian, Mater. Sci. Eng., A 616, 260 (2014)

[20] Z.H. Tan, X.G. Wang, L.H. Ye, G.C. Hou, R. Li, Y.H. Yang, J.L. Liu, J.D. Liu, L. Yang, B. Wang, P. Dong, J.G. Li, Y.Z. Zhou, X.F. Sun, Mater. Sci. Eng., A 761, 138042 (2019)
[21] G. Liu, L. Liu, S.X. Zhang, C.B. Yang, J. Zhang, H.Z. Fu, Acta Metall. Sin. 48, 845 (2012). (in Chinese)

[22] Z.X. Shi, S.Z. Liu, J.R. Li, Acta Metall. Sin. Engl. Lett. 28, 1278 (2018)

[23] X.P. Tan, J.L. Liu, T. Jin, Z.Q. Hu, H.U. Hong, B.G. Choi, I.S. Kim, C.Y. Jo, Metall. Mater. Trans. A 43, 3608 (2012)

[24] S.Y. Ma, X.Q. Li, J.X. Zhang, J.D. Liu, P. Li, Y.J. Zhang, H.X. Jin, W.Y. Zhang, Y.Z. Zhou, X.F. Sun, Q. Zhang, Y.H. Chen, S.C. Mao, J. Alloys Compd. 766, 775 (2018)

[25] L.C. Zhuo, M. Huang, J.C. Xiong, J.R. Li, J. Zhu, Acta Metall. Sin. Engl. Lett. 28, 72 (2015)

[26] B. Dubiel, P. Indyka, I. Kalemba-Rec, A. Kruk, T. Moskalewicz, A. Radziszewska, S. Kac, A. Kopia, K. Berent, M. Gajewska, J. Alloys Compd. 731, 693 (2018)

[27] B. Wang, J. Zhang, X.J. Pan, T.W. Huang, L. Liu, H.Z. Fu, Acta Metall. Sin. 53, 298 (2017). (in Chinese)

[28] W.Y. Ma, Y.F. Han, S.S. Li, Y.R. Zheng, S.C. Gong, Acta Metall. Sin. 42, 1191 (2006). (in Chinese)

[29] W.Z. Wang, T. Jin, J.L. Liu, X.F. Sun, H.R. Guan, Z.Q. Hu, Mater. Sci. Eng., A 148, 479 (2008)

[30] H.B. Long, Y.N. Liu, S.C. Mao, H. Wei, J.X. Zhang, Q.S. Deng, Y.H. Chen, Z. Zhang, X.D. Han, Scr. Mater. 157, 100 (2018)

[31] G.X. Hu, X. Cai, Y.H. Rong, Fundamentals of Materials Science (Shanghai Jiao Tong Press, Shanghai, 2010). (in Chinese)

[32] K.Y. Cheng, C.Y. Jo, T. Jin, Z.Q. Hu, J. Alloys Compd. 509, 7078 (2011)

[33] S. Gao, Z.Q. Liu, C.F. Li, Y.Z. Zhou, T. Jin, Acta Mater. 110, 268 (2016)

[34] H. Murakami, H. Harada, Y. Saito, J. Jpn. Inst. Met. 63, 723 (1999)

[35] M. Simonetti, P. Caron, Mater. Sci. Eng., A 254, 1 (1998)

[36] C.N.R. Rao, K.J. Rao, Phase Transitions in Solids (McGraw-Hill Inc. International Book Company, New York, 1978)

[37] Y. Adda, J.M. Dupouy, J. Philibert, Y. Quéré, Eléments de Métallurgie Physique, vol. 4 (La Documentation Francaise, Paris, 1979)

[38] Z.D. Fan, D. Wang, C. Liu, G. Zhang, J. Shen, L.H. Lou, J. Zhang, Acta Metall. Sin. Engl. Lett. 30, 878 (2017)

[39] D.A. Porter, K.E. Easterling, Phase Transformations in Metals and Alloys, 2nd edn. (Chapman \& Hall, New York, 1992) 